\title{
Imaginario social, memoria colectiva y construcción de territorios en torno a los 30 años del golpe militar en Chile
}

\author{
Mg. Alberto Javier Mayorga Rojel ${ }_{* * *}^{* *}$ \\ Mg. Luis Nitrihual Valdebenito \\ Dr. Juan Manuel Fierro Bustos
}

Recibido: 20 de febrero de 2012 Aprobado: 27 de marzo de 2012

\begin{abstract}
Resumen
En el presente trabajo se establece la necesidad de reflexionar acerca del proceso de configuración de la "memoria colectiva" y de los "territorios" compartidos en torno al 11 de septiembre de 1973 en el marco de los 30 años del Golpe Militar en Chile desde una perspectiva socio-semiótica. Por lo tanto, nuestra propuesta establece como objetivos centrales los siguientes: 1) presentar, por una parte, una descripción y discusión conceptual pertinente acerca de las nociones de "memoria colectiva", "texto", "fronteras" y "territorios", considerando los planteamientos teóricos de Maurice Halbwachs, Manuel Antonio Garretón, René Kaës, Iuri Lotman, Cristina Peñamarín, entre otros. 2) Y por otra, aportar a la reflexión en torno a los conceptos mencionados a través del análisis de una práctica discursiva institucional, entrega de resultados y consideraciones finales respecto al objeto de nuestro interés analítico.
\end{abstract}

Palabras clave: discurso político, sociosemiótica, imaginarios sociales, memoria colectiva, golpe militar en Chile.

\footnotetext{
El presente artículo se suscribe al programa de investigación en Imaginarios Sociales, Discurso, Cultura y Poder desarrollado en el Grupo de Investigación en Comunicación y Saberes Críticos del Programa de Magíster en Ciencias de la Comunicación, Facultad de Educación, Ciencias Sociales y Humanidades, Universidad de La Frontera (Temuco, Chile). Además, agradecemos a la Mg. Rocío López y Mg. Yassna Sepúlveda por su dedicación y participación en el proceso de análisis del discurso realizado en el marco del presente artículo.

* Magíster en Ciencias de la Comunicación. Académico del Departamento de Lenguas, Literatura y Comunicación. Facultad de Educación, Ciencias Sociales y Humanidades. Universidad de La Frontera. Temuco, Chile. Casilla 54-D. Correo electrónico: amayorga@ufro.cl

.*. Magíster en Ciencias de la Comunicación. Académico del Departamento de Lenguas, Literatura y Comunicación. Facultad de Educación, Ciencias Sociales y Humanidades. Universidad de La Frontera. Temuco, Chile. Casilla 54-D. Correo electrónico: anitrihual@ufro.cl

"... Doctor en Ciencias Humanas. Académico del Departamento de Lenguas, Literatura y Comunicación. Facultad de Educación, Ciencias Sociales y Humanidades. Universidad de La Frontera. Temuco, Chile. Casilla 54-D. Correo electrónico imfierro@ufro.cl
} 


\title{
Social Imaginary, Collective Memory, and Construction of Territories after 30 Years of the Military Takeover in Chile
}

\begin{abstract}
This article deals with the need for making a reflection on the configuration process of "collective memory" and "territories" shared in relation to September 11 th, 1973 after 30 years of the military takeover in Chile, from a socio-semiotic point of view. Therefore, our proposal involves the following main objectives: 1) on the one hand, to present a conceptual description and discussion in relation to concepts such as "collective memory," "text," "borderlines," and "territories," based on the theoretical statements of Maurice Halbwachs, Manuel Antonio Garretón, René Kaës, Luri Lotman, Cristina Peñamarín, among others; 2) on the other hand, to make a contribution to a reflection on the already named concepts by analyzing an institutional discourse practice, delivering results and final considerations in relation to the purpose of our analytical interests.
\end{abstract}

Key words: Political speech; socio-semiotics; social imaginaries; collective memory; military takeover in Chile. 


\section{Introducción}

El 11 de septiembre de 1973 no es una fecha cualquiera en la historia de Chile y mucho menos para la gran mayoría de los chilenos. Por el contrario, el martes 11 de septiembre de 1973 es un día significativo en el marco de la memoria colectiva de un país y, en términos políticos, corresponde al día en que se observa una ruptura violenta en el desarrollo democrático experimentado en Chile y, por consiguiente, se evidencia el quiebre del orden constitucional de un país, producto del golpe de Estado concertado por las élites político-militares de Chile y el extranjero.

Así, entonces, este acontecimiento que marca la historia de Chile durante la segunda mitad del siglo XX y que tuvo consecuencias políticas (quiebre del desarrollo democrático y del orden constitucional), sociales (violación de los derechos humanos, aumento de la pobreza y desfragmentación del movimiento obrero y campesino) y económicas ${ }^{1}$ (aplicación del modelo económico de libre mercado y reducción del gasto público en educación y salud) es un evento significativo vigente dentro de las dinámicas tanto sociales, como mediáticas y políticas presentes en el Chile contemporáneo. Por tal razón, la intervención militar en el espacio público, el derrocamiento del gobierno democrático de Salvador Allende Gossens y la violación de los derechos humanos corresponden a sucesos que forman parte de la "memoria colectiva" de una nación y que, 30 años después de lo ocurrido, se transforman en las figuras determinantes de la dinámica de

1 En el marco de la crisis económica (década del 80), O`Donnell (1993: 85-86) plantea que países como Chile, Bolivia y Argentina, compartieron los siguientes rasgos en común: 1) un Estado que como principio del orden tiene una autoridad minúscula sobre la conducta de muchos actores (...); 2) un movimiento obrero completamente derrotado en el sentido de que ya no es capaz de oponerse a las políticas neoliberales, excepto con protestas desagregadas y efímeras; 3 ) una clase capitalista que sustancialmente se devoró así misma, con los ganadores metamorfoseándose en conglomerados centrados financieramente y orientados hacia fuera (...); y 4) un sentimiento generalizado de que la vida bajo una inflación continua e incierta es tan insoportable que cualquier solución es preferible, incluso si esa solución ratifica un mundo aún más desigual en el que se han perdido muchas formas de sociabilidad solidaria. configuración de los discursos públicos. Es decir, imbricación de enunciados dentro de los relatos acerca de lo acontecido o, mejor dicho, portadores de imaginarios sociales que se cristalizan en la memoria de un conjunto de individuos integrantes de una sociedad y que, no menos importante, comparten una experiencia y los recuerdos de un período de la historia.

En este sentido, cabe la necesidad de recalcar que el Golpe Militar² de 1973 acontecido en Chile es un hecho que marca el fin de un tipo de proyecto país que se venía articulando desde principios del siglo XX sobre la base de los cambios constitucionales de 1925, un sistema de partidos políticos integrado en los diversos sectores sociales del país, la conformación de un Estado-nación, un modelo de desarrollo económico centrado en la industrialización y modernización de los sistema de producción nacional y el auge de una masa intelectual compenetrada con los problemas del país y reconocida en el mundo (Gabriel Mistral, Pablo Neruda, entre otros).

Por lo tanto, asumimos que las distintas generaciones de individuos que forman parte de un

2 Desde nuestra perspectiva, podemos afirmar que las dictaduras en América Latina corresponden a una instancia donde la implementación de las reformas neoliberales han configurado la doble dimensión del Estado: 1) Se debilita su capacidad para redistribuir equitativamente las riquezas, cohesionar a la ciudadanía a partir de un proyecto común y gestionar la eficiente participación democrática (no meramente instrumental) de la sociedad civil. 2) Se fortalece su papel de interlocutor (no interventor) entre el capital internacional y el mercado local, regulador de la relación entre el mercado y la sociedad civil, dinamizador de las relaciones internacionales como mecanismo de compenetración económica-política entre los países industrializados y las naciones en vías de desarrollo, y, finalmente, facilitador de las modificaciones necesarias (desregulaciones) para la subsistencia de determinados sistemas productivos y/o cambios de éstos. Por su parte, Garretón (2000: 1 16) plantea que: "El Estado combina, por un lado, dimensiones simbólicas, institucionales, instrumentales, y actorales o de agente relativamente autónomo. Por otro lado, ejerce funciones coercitivas, reguladores, redistributivas, integrativas, dependiendo de qué esfera de la sociedad se trata". En el fondo, para el mencionado autor el Estado es el conjunto de instituciones y organizaciones que tienen el carácter público y que en un espacio territorial determinado poseen el monopolio legítimo de la fuerza. En este sentido, el Estado cristaliza las diversas relaciones de poder y dominación que se observan en la sociedad y, además, posee la capacidad de ser un agente de la unidad nacional y el promotor del modelo de desarrollo que impulsa a la nación. 
país, también forman parte de su historia y se reconocen en ella mediante los distintos procesos de socialización y prácticas colectivas. De ahí la importancia de comprender que nuestra "memoria colectiva" se elabora a partir de un momento histórico o punto de inflexión referencial para la mayoría de los chilenos por su relevancia en virtud de las transformaciones ocurridas en el país, es decir, nuestra "memoria colectiva" es producto de nuestro pasado, es la reconstrucción de nuestro pasado mediante la acción comunicativa $^{3}$ simbólica, y si bien se manifiesta a través de diversas formas, creemos que la práctica discursiva -en su sentido amplio- precisa el establecimiento de un espacio de encuentro y reconocimiento con el pasado y el conjunto de significaciones ${ }^{4}$ compartidas por los miembros de un grupo.

Así, el recuerdo y la significación compartida de un periodo o hecho ${ }^{5}$ como acción social realizada por un grupo o sociedad en el marco de un espacio y tiempo específicos, configura las bases de la "memoria colectiva" capaz de envolver -pero no confundirse con ella y mucho menos determinar su significación absoluta- las memorias individuales para apropiarse de una dimensión temporal esencial del hombre como es el caso del "pasado" y, en efecto, mediante el uso de prácticas discursivas instituir imaginarios sociales acerca del pasado, pero con la intención

3 Para René Kaës (1996: 177) "la memoria colectiva está estrechamente ligada a una experiencia vivida integrada a la historia de un grupo y, por otra parte, se define en relación con ésta. Aquellos que no han compartido esa historia no pueden comunicar con esta memoria".

4 Respecto a la noción de significación, Manuel Antonio Baeza (2003: 85) la entiende como "el producto del ejercicio de la facultad organizadora mental humana frente al problema que le plantea el cosmos, la naturaleza, el mundo social, el tiempo, el espacio, etc. No obstante, para que cosmos, naturaleza, mundo social, espacio, tiempo, etc., tengan existencia real, cada uno de ellos debe encontrase dotado de sentido subjetivamente atribuido".

5 Utilizaremos el concepto de "periodo" o "hecho" histórico en el sentido propuesto por Maurice Halbwachs (2004). Es decir, en el proceso de activación de la "memoria colectiva" se asume que con el pasar del tiempo el recuerdo de los hechos se aleja o se tiende a perder precisión (detalles), por tal razón no existe un recuerdo - necesariamente - exhaustivo de un hecho sino que por el contrario establecemos un instancia de recuerdo del conjunto. de articular un sentido de consenso acerca de lo ocurrido que permita proyectarnos en el presente un futuro cohesionado como país.

En este sentido, planteamos nuestro acuerdo con lo propuesto por Manuel Antonio Garretón (2003: 215-216):

[...] la necesidad de una memoria colectiva compartida sobre lo fundamental, aunque se discrepe muy profundamente sobre causas y consecuencias. Y lo cierto es que nuestro pasado, es decir, nuestro presente, es decir, nuestra proyección como sociedad o comunidad hacia adelante, nuestro núcleo fundante y lo único común que tenemos, son ciertas cristalizaciones históricas, ciertos hitos constituyentes.

Pues bien, durante el 2003 se llevó a cabo una diversidad de actos conmemorativos de los 30 años del Golpe Militar en Chile. En el marco de un conjunto de actividades de carácter político, social y cultural, donde se manifiesta la "memoria colectiva" en torno a este hito trascendental de la historia reciente de Chile, Ricardo Lagos Escobar ${ }^{6}$, Presidente de la República en ese entonces, pronunció un discurso en el Palacio de la Moneda con motivo de la ceremonia para recordar los 30 años del 11 de septiembre de 1973. No cabe

6 Declaración de Ricardo Lagos producto de una consulta acerca de lo que diría en el marco de la conmemoración de los 30 años del 11 de septiembre de 1973. Entrevista completa publicada (domingo 31 de agosto de 2003) por el diario argentino Página 12.

"Hablaré de estos 30 años. Y también de lo que pasó allí ese día, por supuesto. Estamos trabajando en la apertura de la puerta de Morandé 80. (Una puerta lateral del palacio de gobierno que Pinochet tapió). Le doy un sentido republicano, de apertura. La abriré para el 11 de septiembre. Morandé 80 era la puerta por donde entraba el ciudadano presidente a la Moneda y salía de la Moneda. Se construyó a comienzos del siglo XX, cuando el presidente vivía en el sector privado del palacio presidencial. Así, si el presidente entraba y salía por razones privadas, la guardia no tenía necesidad de rendirle honores. Es un simbolismo del sistema democrático. Y si fuimos capaces el 11 de marzo del 2000, cuando asumí, de abrir las puertas de la Moneda para que la gente pudiera transitar por el medio del palacio todos los días, me pareció que a 30 años del golpe abrir Morandé 80 era el símbolo del restablecimiento de nuestras tradiciones republicanas". 
duda de que esta instancia conmemorativa tuvo una gran importancia -en términos políticos y sociales- producto del prestigio social y relevancia nacional que posee la figura del Presidente de la República para el conjunto de personas que integran la sociedad chilena. Por tal razón, en este trabajo pretendemos analizar una práctica discursiva institucional para reconocer el imaginario social del 11 de septiembre de 1973 en el marco de los 30 años del Golpe Militar en Chile, para lo cual, primero, se presenta una acotada descripción teórica de los conceptos de imaginarios sociales y "memoria colectiva", luego establecemos la metodología y el modelo de análisis que se utilizará, para obtener, finalmente, resultados y conclusiones respecto al objeto de nuestro interés analítico.

\section{Texto, frontera y territorio}

La obra de Iuri Lotman se eleva, en la semiótica, como un territorio propio y nutrido por una interdisciplinariedad que hace del autor ruso uno de esos autores que pueden ser leídos desde múltiples posiciones, sin agotar su riqueza como propuesta analítica, estética y, por qué no, política.

Nacido en Petrogrado, Lotman fue profesor de la Universidad de Tartú en Estonia donde desarrolló una extensa obra en campos como la literatura, la semiótica y la teoría cultural. Su obra, en esta medida, avanza desde sus iniciales trabajos en literatura rusa del siglo XVIII hacia una concepción de la cultura en términos de diálogos textuales.

En este sentido, resulta lógico pensar que su obra es más que una semiótica específica, es "una semiótica de la cultura" que es la categorización que se le ha dado y que advierte al lector el sinnúmero de objetos que son analizados por la Escuela de Tartú-Moscú.

La cuestión central de la cual parte la obra de Lotman es una redefinición de la noción de texto, ya no solo desde un punto de vista lingüístico, sino como parte constituyente de un sistema mayor denominado semiosfera. En esta medida: "Todo el espacio semiótico puede ser considerado como un mecanismo único (...) La semiosfera es el espacio semiótico fuera del cual es imposible la existencia misma de la semiosis" (Lotman, 1996:24).

De modo que en un sentido amplio, la semiótica de la cultura se refiere al texto como una comunicación construida en un determinado sistema sígnico. En esta medida, se entiende la amplitud de objetos analizables desde esta perspectiva: un ballet, una pintura, una pieza musical, un libro, etc.

El texto visto así es el modo de organización básico y fundamental de la vida cultural y no solo un portador informacional. El texto es la expresión del devenir temporal y la concreción del espacio. Como ha señalado Julia Kristeva (2007), la idea de texto como un modelo reducido de la cultura es interesante pues transforma al texto en una actividad compleja e interactiva donde surge el significado. De este modo, el texto genera el significado del lenguaje y no a la inversa.

Las siguientes son algunas de las funciones que Lotman atribuye a los textos:

1. Entre destinador y destinatario, el texto cumple una función de portador de información.

2. Entre el auditorio y la tradición cultural el texto cumple una función de memoria cultural cuya función es establecer cristalizaciones e hitos relevantes.

3. En el trato del lector con el texto, el texto deja de ser un mero portador de información y deviene un interlocutor con alto grado de autonomía. Sobre este aspecto, Lotman (1996:97) señala: "En este punto, el texto deja de ser un eslabón pasivo de la transmisión de alguna información constante de entrada (...) El deslizamiento entre ordenamientos estructurales de diverso género, le confiere al texto posibilidades de sentido 
mayores que aquellas de que dispone cualquier lenguaje tomado por separado".

A estas tres funciones que nos interesa resaltar, habría que agregar una cuarta que resulta interesante:

4. En el trato del lector con el texto, el texto no es solo un portador de información con alto grado de autonomía sino, también, un portador sentimental y un desencadenante sentimental.

El texto es el origen de la vida cultural y se ubica en la semiosfera en coexistencia con otros múltiples textos al menos en dos sistemas: un sistema modelador primario, que corresponde a todos los textos derivados de las lenguas primarias y; un sistema modelador secundario, que son textos como el ballet, la ópera o la pintura, entre otros.

Por otro lado, la existencia de una vida organizada en textos exige -como ya hemos señalado- un material exterior a la semiosfera y que constantemente está siendo traducido para su asimilación y para la formación de nuevos textos. Como señala Peñamarín, siguiendo a Lotman (1996:143): "La cultura, "memoria no hereditaria de la colectividad", implica la construcción de un sistema de reglas para la traducción de la experiencia en texto".

De este modo, desde la concepción del texto como entidad homogénea y estable, surge el trabajo bajtiniano y postbajtiniano, retomado, entre otros, por Lotman, que destaca el juego límite de los textos y su exterior no organizado, y también el juego de traducciones entre textos de la propia semiosfera.

Siguiendo esta concepción, la cuestión de la memoria es, antes que del hito (el monumento, la biografía, etc.), del procedimiento semiológico mediante el cual se organiza la experiencia en textos, que son organismos plurivocálicos y dialógicos. En esta medida, la memoria no es un mero depósito de saberes sino un dispositivo que, como señala Agamben (2003) siguiendo a Foucault, tiene una función estratégica concreta, inscrita en una relación de poder.

La condición de la dialogicidad textual es, en esta medida, siempre posible y no guarda contradicción con la incomprensión, por ejemplo, entre dos interlocutores. Esto último tiene relación con la apertura o no al encuentro y entendimiento con el otro. Epistemológicamente el diálogo se da entre textos y el proceso de significación ocurre entre emisores y receptores con variados códigos. Sostenemos como Peñamarín (2006) que el malentendido y el desencuentro parecen ser estructurales a toda comunicación (Peñamarín, 2006).

La memoria como un dispositivo no es, en esta medida, la enumeración de hechos y la cristalización de héroes o acciones sino el dinámico proceso de formación del sentido, traducido en texto y que interviene en nuestra vida tanto racional como pasional.

\section{Memoria colectiva. Algunas precisiones conceptuales}

Como venimos señalando, la traducción de la experiencia en textos es una actividad sensible, compleja en la medida que implica una actividad de poder verificable en el continuo desplazamiento o marginación de otros sentidos. Ahora bien, si toda experiencia es siempre traducible en textos, la lucha de poder se centra, más bien, en el caso de la memoria, en la pugna por cuáles dispositivos se elevan como parte de espacio público y de la visibilidad que hegemoniza determinadas formas de sentir y observar la realidad.

En el caso de la memoria, se trata de construir dispositivos que construyan un territorio compartido que aglutine los sentires y saberes de una colectividad.

Con el objeto de avanzar en la descripción de los conceptos centrales que dan sentido a nuestro trabajo, nos planteamos la necesidad de 
identificar algunas definiciones para comprender el concepto de "memoria colectiva" y, a su vez, establecer algunas breves precisiones respecto al mismo concepto desde una perspectiva sociológica contemporánea.

Es decir, si bien nuestra intención no es presentar un desarrollo acabado del concepto, no es menos importante asumir que las ideas propuestas acerca de la "memoria colectiva", y que marcan la lógica del presente apartado, se sustentan en las reflexiones y propuestas teóricas trabajadas por varios autores contemporáneos: Maurice Halbwachs (2004), Manuel Antonio Garretón (2000, 2003), Manuel Antonio Baeza (2001, 2003) y René Kaës (2006).

Conforme a esta breve presentación de los límites e intenciones de este punto dentro del trabajo, quisiéramos comenzar por precisar lo que entenderemos por "memoria colectiva", tomando como base la propuesta de Maurice Halbwachs (2004: 36):

[...] podemos hablar de memoria colectiva cuando evocamos un hecho que ocupaba un lugar en la vida de nuestro grupo y que hemos planteado o planteamos ahora en el momento en que lo recordamos, desde el punto de vista de este grupo.

Sin embargo, no podemos atribuir a la acción de evocar, enunciar, nombrar o mencionar un hecho del pasado como naturaleza suficiente que permita establecer la "memoria colectiva" de un grupo. Si nos quedamos con esta primera impresión -creemos- estaríamos legitimando una concepción de la "memoria colectiva" como la mera identificación -e incluso-, como simple enumeración de hechos históricos que son determinados de forma objetiva producto de un rigor científico articulado sobre la base de un adecuado tratamiento y análisis de cualquier hecho histórico. O sea, estaríamos negando la condición de subjetividad ${ }^{7}$ y la condición políti-

7 Desde la hermenéutica, es posible desarrollar una relación con ca al proceso de configuración de una "memoria colectiva". De este modo, es posible concordar con lo postulado por Maurice Halbwachs (2004: 56):

Evidentemente, si la memoria colectiva no tuviera más base material que la series de fechas o listas de hechos históricos, su papel en la fijación de nuestros recuerdos sería sólo secundario.

Por consiguiente, en palabras de Manuel Antonio Baeza (2003: 99):

La memoria colectiva no es otra cosa que un conjunto de significaciones socialmente compartidas del pasado; no se trata de una colección de recuerdos de acontecimiento emblemáticos, sino de sentidos adosados a tales o cuales hechos que, efectivamente adquieren así un carácter sobresaliente.

Al reflexionar sobre la base de lo mencionado, podemos asumir -a priori- que los hechos ocurridos a partir del 11 de septiembre de 1973 han dejado una marca significativa en la historia de Chile y en los individuos que conforman determinados grupos sociales. Esto quiere decir que los individuos que forman parte de un grupo establecen los contenidos y las significaciones en relación con los hechos del pasado dentro de un plano común de reconocimiento, o sea, se articula su "memoria colectiva" mediante la acción de "compartir algo en común" producto de la relación intragrupal que funda una colectividad y su respectiva identidad.

\footnotetext{
el concepto de subjetividad y "memoria colectiva", es decir, en el marco de esta relación la denominada cuestión hermenéutica nos permite comprender que la existencia de una conciencia histórica y de significación respecto a dicha conciencia implica el hacer consciente los propios prejuicios (marcos sociales de referencia) en virtud del encuentro con la tradición y que guían al individuo en la comprensión de un hecho histórico. Por ende, la experiencia hermenéutica, según las palabras de Gadamer (1998: 218): "no consiste en que algo esté afuera y tienda a entrar dentro, sino más bien al hecho de ser captado por algo y justamente en virtud de lo que nos capta y posee, estamos abiertos a lo nuevo, a lo distinto, a lo verdadero".
} 
Volvamos -nuevamente- a Manuel Antonio Baeza (2008: 189 y 190)

La subjetividad individual responsable de significación del mundo se revela sin embargo insuficiente para estos efectos $y$, por lo mismo, debe enriquecerse con significaciones que son, en definitiva, compartidas. [Por tal razón] las figuras imaginario-sociales ${ }^{8}$ son algo así -y se comportan como tales- como una verdad conveniente que parece satisfactoria a un grupo social...

Evidentemente, los individuos de un grupo se encuentran estrechamente ligados mediante la significación de una experiencia vivida en el marco de su historia individual y de la historia del país donde habitan; por tal razón la "memoria colectiva" y la "memoria individual" se complementan, por un lado, en la medida que la primera logra sustentar el trabajo de construcción de la segunda y, por otro, la "memoria individual" requiere -muchas veces cuando se trata de hechos ocurridos en periodos alejados del presente de enunciación- la colaboración de las demás memorias individuales, pero con la condición de la existencia de puntos en común entre una y otras.

Asistimos acá, en realidad, a la investidura de relevancia que posee la "memoria colectiva" para las diversas sociedades al considerarla como eje central, o mejor dicho, como agente vital para la reproducción de cada una de las sociedades en su sentido singular o particular.

De modo que, desde la perspectiva de Manuel Antonio Baeza (2003: 100):

...el tiempo pasado no es histórico por el sólo hecho de ser tiempo transcurrido ${ }^{9} \mathrm{y}$ cargado de acontecimientos, o sea tiempo

8 "El concepto de imaginarios sociales, desde un punto de vista fenomenológico, evoca por ende la facultad social de llevar a cabo significatividad con sentido práctico para abordar precisamente la experiencia existencial compartida, sin olvidar para estos propósitos, por cierto, aquello que A. Giddens llama un registro reflexivo" (Baeza, 2008: 190).

9 Las cursivas son nuestras. presente que dejó de serlo, sino por el hecho de ser tiempo significado colectivamente.

Por consiguiente:

En realidad esta dimensión del tiempo que es el pasado es uno de los ámbitos más asociados al tema de la significación fluctuante. Sin ella, por ejemplo, los acontecimientos trágicos del Chile de los 70-80 no tendrían ninguna posibilidad de repercutir simbólicamente en el presente del Chile contemporáneo y, por supuesto, el país estaría expuesto a revivir parecidas experiencias sin lecciones del pasado (Baeza, 2003: 100)

En síntesis, y para concluir el presente apartado, diremos que la "memoria colectiva" corresponde a una dimensión vital para la constitución de los individuos como sujetos sociales, los cuales construyen o (re)construyen su pasado como base para la estructuración de un proyecto país ${ }^{10}$. En consecuencia, siguiendo la reflexión de René Kaës (2006), diremos que la "memoria colectiva" es el conjunto de recuerdos y significaciones de estos, que son transmitidas a los miembros de un grupo o sociedad y que adquieren sentido producto del vínculo intergeneracional en un tiempo y espacio determinados.

\section{Propuesta metodológica}

En el plano epistemológico, entendemos que la realidad social es construida por los individuos mediante la acción intersubjetiva que se articula producto de las diversas interacciones sociales. Incluso, se asume que en el marco del proceso comunicativo que se atribuye como acción propia de los individuos, estos comparten significados en común respecto a la realidad so-

10 En palabras de Manuel Antonio Garretón (2003: 216): "No hay proyecto de país que ni implique elaboración de la memoria, aunque ésta no agote el contenido de un proyecto. Y la falta actual de un proyecto de país o estatal nacional en parte se explica por la amnesia parcial en estos años. Es sólo en este 2003, que parece desgarrarse el tupido velo que habíamos tejido sobre nuestra historia contemporánea y que comienza a hablarse de los que se ha callado hasta ahora". 
cial construida. Por lo tanto, es posible estudiar un fenómeno desde una perspectiva cualitativa compatible con los fundamentos teóricos que sustentan el marco comprensivo y descriptivo de nuestro estudio, donde -además- se asume como parte del trabajo de análisis de un investigador la intención de objetivar ${ }^{11}$, en la medida de lo posible, un fenómeno constituyente de una realidad social.

En el mismo sentido y como una manera de complementar lo anterior, destacamos la relación que existe entre los imaginarios sociales y la producción discursiva en toda sociedad moderna, puesto que dicha relación nos permite comprender que el discurso es el reflejo de una lucha entre significados dominantes y dominados, entre las estrategias de construcción de sentido de los múltiples contenidos expuestos y las variadas interpretaciones que puede hacer un individuo al tomar como elementos referenciales las propias experiencias. O sea, se tendrá que considerar que la producción discursiva en diversos ámbitos sociales y su posterior entrada al juego de las interpretaciones de los individuos faculta a un sector de la sociedad para establecer una estrategia de poder mediante el control de la práctica discursiva como mecanismo necesario para la construcción de una realidad y (re)configuración de la "memoria colectiva".

Así, entonces, para cumplir con el objetivo central del presente estudio se ha elaborado un modelo de análisis sobre la base de las perspectivas teóricas trabajadas por J. Courtés (1995) y J-C. Giroud y L. Panier (1988), que es empleado particularmente para el análisis de discursos políticos, lo que nos permitirá establecer la presencia de figuras, roles, valores temáticos, fases na-

11 Para los fines de nuestra investigación, se comparte la propuesta de Baeza (2008: 45) respecto a la objetivación entendida "- en un sentido simple - como un compromiso entre lo materialmente dado y lo subjetivamente entendido como dado; $|y|$ - en un sentido complejo - como un esfuerzo intelectual riguroso para convertir en evidencias aspectos visibles y no visibles de la realidad" |... realidad que - desde nuestro punto de vista - se hace presente en el discurso, o sea el discurso es un dispositivo que materializa el imaginario social en el entramado de relaciones sociales. rratológicas, contextos que enmarcan el sentido de lo enunciado y elementos de la estructura de significación que sustentan la lógica del discurso presidencial en conmemoración de los 30 años del 11 de septiembre de 1973.

En este sentido, la matriz de análisis propuesta nos permite estudiar el discurso presidencial de Ricardo Lagos, con la intención de describir el imaginario social construido en torno a la conmemoración de los 30 años del 11 de septiembre de 1973 y, por ende, se establece un conjunto de categorías de análisis afines con la intención de determinar aquellos elementos discursivos y las relaciones de significación que sustentan los constructos de sentido acerca de la simbólica fecha.

Así, entonces, el material que será analizado en este estudio lo constituye el siguiente corpus:

\begin{tabular}{|l|l|}
\hline \multicolumn{2}{|c|}{ IDENTIFICACIÓN DEL CORPUS } \\
\hline a) Institución & $\begin{array}{l}\text { Presidencia de la República } \\
\text { de Chile }\end{array}$ \\
\hline b) Tipo de texto & Discurso Presidencial \\
\hline c) Tipo de discurso & Político \\
\hline d) Actor/ Hablante & Ricardo Lagos Escobar \\
\hline e) Lugar de emisión & Palacio de la Moneda \\
\hline f) Fecha & $\begin{array}{l}\text { Jueves, 11 de septiembre de } \\
2003\end{array}$ \\
\hline g) Contexto & $\begin{array}{l}\text { Acto de conmemoración de } \\
\text { los 30 años del 11 de sep- } \\
\text { tiembre de 1973 }\end{array}$ \\
\hline
\end{tabular}

Tabla I. Elaboración propia. Identificación del corpus analizado en el presente trabajo

En definitiva, si las representaciones discursivas están sustentadas en un principio ideológico que logra unificar el sentido de un discurso, entonces se hace evidente la facultad que poseen los imaginarios sociales para categorizar, 
rotular, articular y disponer de la construcción social de sentido en torno a un colectivo, sujeto u objeto sobre la base de creencias compartidas socioculturalmente $y$, de esta manera, se establece un discurso verosímil capaz de reforzar en la "memoria colectiva" los imaginarios que se han transmitido por medio de las diversas operaciones socializadoras de cada comunidad.

\section{Presentación de los resultados}

\subsection{Identificación de figuras, roles y valores temáticos}

A continuación se procede a presentar un cuadro resumen de las figuras, roles y valores temáticos de mayor relevancia, presentes en el discurso presidencial de Ricardo Lagos.

\begin{tabular}{|c|c|c|c|}
\hline \multicolumn{4}{|c|}{ MODELO DE ANÁLISIS DEL DISCURSO } \\
\hline \multicolumn{4}{|c|}{ NIVEL DE ANÁLISIS: ESTRUCTURA DEL DISCURSO } \\
\hline Figuras / Rol & \multicolumn{2}{|c|}{ Valores temáticos } & Situaciones discursivas \\
\hline $\begin{array}{l}\text { Consiste en identificar } \\
\text { las distintas figuras } \\
\text { (actores, instituciones, } \\
\text { tiempo(s), lugar(es)), que } \\
\text { aparecen en el discurso } \\
\text { y el papel que se les } \\
\text { asigna a cada uno en el } \\
\text { relato. }\end{array}$ & \multicolumn{2}{|c|}{$\begin{array}{l}\text { Es el sentido que se construye a partir de las rela- } \\
\text { ciones entre las figuras y sus recorridos figurativos. } \\
\text { Por lo tanto, las figuras tienen un valor a partir de su } \\
\text { relación con otras figuras. }\end{array}$} & $\begin{array}{l}\text { Todo texto dispone a } \\
\text { los actores en un(os) } \\
\text { tiempo(s) y en un (os) } \\
\text { lugar(es), permitiendo } \\
\text { esta disposición la lec- } \\
\text { tura de un texto a partir } \\
\text { de la identificación de } \\
\text { situaciones discursivas } \\
\text { (relaciones entre figu- } \\
\text { ras). }\end{array}$ \\
\hline Fase de manipulación & Fase de competencia & Fase de performancia & Fase de sanción \\
\hline $\begin{array}{l}\text { Consiste en indicar la } \\
\text { relación entre quien } \\
\text { hace-hacer, mediante } \\
\text { persuasión, amenaza, } \\
\text { seducción, promesa, } \\
\text { etc., algo a determina- } \\
\text { dos sistemas-actores. }\end{array}$ & $\begin{array}{l}\text { Consiste en identificar } \\
\text { las características que } \\
\text { hacen a un sistema- } \\
\text { actor manipular a otro. }\end{array}$ & $\begin{array}{l}\text { Consiste en identificar } \\
\text { las transformaciones } \\
\text { que un sistema-actor } \\
\text { realiza sobre otro. }\end{array}$ & $\begin{array}{l}\text { Consiste en identificar } \\
\text { las posibles consecuen- } \\
\text { cias expresadas en el } \\
\text { relato para lograr la ma- } \\
\text { nipulación de un siste- } \\
\text { ma-actor sobre otro. }\end{array}$ \\
\hline \multicolumn{4}{|c|}{ NIVEL DE ANÁLISIS: ESTRUCTURA DE LA SIGNIFICACIÓN } \\
\hline $\begin{array}{l}\text { Relaciones de contra- } \\
\text { riedad }\end{array}$ & \multicolumn{2}{|c|}{ Relaciones de contradicción } & $\begin{array}{l}\text { Relaciones de comple- } \\
\text { mentariedad }\end{array}$ \\
\hline $\begin{array}{l}\text { Relación lógica entre A y } \\
\text { B, y entre NO B y NO A. }\end{array}$ & \multicolumn{2}{|c|}{ Relación lógica entre A y NO A, y entre B y NO B. } & $\begin{array}{l}\text { Relación lógica entre A y } \\
\text { NO B, y B y NO A. }\end{array}$ \\
\hline
\end{tabular}

Tabla II. Elaboración propia. Componentes del modelo de análisis utilizado en el presente trabajo 
Imaginario social, memoria colectiva y construcción de territorios en torno a los 30 años del golpe militar en Chile

\begin{tabular}{|l|l|l|}
\hline \multicolumn{1}{|c|}{ Figura } & \multicolumn{1}{|c|}{ Rol } & \multicolumn{1}{c|}{ Valor Temático } \\
\hline $\begin{array}{l}\text { Presidente de la República } \\
\text { Ricardo Lagos }\end{array}$ & $\begin{array}{l}\text { Mandatario de la nación chilena que recuerda y reflexiona } \\
\text { sobre un hecho ocurrido el 11 de septiembre de 1973 y } \\
\text { (figura / actor) } \\
\text { a seguir avanzando en la construcción del país. }\end{array}$ & $\begin{array}{l}\text { Esta figura tiene el } \\
\text { valor de reflexión, mo- } \\
\text { tivación y evaluación. }\end{array}$ \\
\hline Presidente Allende & $\begin{array}{l}\text { Referente del que hace uso / mención la figura del Pre- } \\
\text { sidente de la República Ricardo Lagos para evocar un } \\
\text { momento de dolor que marcó la historia de Chile. }\end{array}$ & $\begin{array}{l}\text { Esta figura tiene el } \\
\text { valor de memoria y } \\
\text { sacrificio. }\end{array}$ \\
\hline (figura / actor) & $\begin{array}{l}\text { Fecha indicadora de un momento doloroso ocurrido hace } \\
\text { 11 de septiembre de } 1973 \text { añ en la historia de Chile. }\end{array}$ & $\begin{array}{l}\text { Esta figura tiene el } \\
\text { valor de memoria. }\end{array}$ \\
(figura / tiempo) & $\begin{array}{l}\text { Espacio físico donde se desarrolla el acto reflexivo de de } \\
\text { la figura del Presidente de la República Ricardo Lagos } \\
\text { acerca del momento histórico ocurrido el 11 de sep- } \\
\text { tiembre de 1973. }\end{array}$ & $\begin{array}{l}\text { Esta figura tiene el } \\
\text { valor de lugar. }\end{array}$ \\
\hline La Moneda & $\begin{array}{l}\text { Representación de los habitantes, territorio y gobierno } \\
\text { que conforman la Nación chilena afectada por la situa- } \\
\text { ción ocurrida el 11 de septiembre de 1973 y que en la } \\
\text { actualidad está inserta en un proceso de consolidación } \\
\text { democrática. }\end{array}$ & $\begin{array}{l}\text { Esta figura tiene el } \\
\text { valor de reflexión y } \\
\text { desarrollo. }\end{array}$ \\
\hline Chile & \multicolumn{2}{|c|}{ (figura / actor) }
\end{tabular}

Tabla III. Elaboración propia. Identificación de figuras, roles y valores temáticos

\subsection{Identificación de fases narratológicas}

En este nivel de análisis nos encontramos frente a un desarrollo más abstracto donde el texto se organiza mediante el componente narrativo. Aquí, se despliega una serie de situaciones (estados) y de acciones (transformaciones) entre esos estados. En este análisis se clasifican los enunciados de un texto en dos categorías: los enunciados de estados (ser) y los enunciados de operaciones (hacer), para así establecer relaciones entre los enunciados de acuerdo con determinadas fases.

\section{1) Fase de manipulación}

En el proceso de análisis que corresponde a esta fase inicial del esquema narrativo se identificaron los actantes y papeles actanciales de las figuras más representativas existentes en el nivel discursivo. De esta forma, la figura del Presiden- te de la República Ricardo Lagos es el actante destinador (hace hacer) de la manipulación por persuasión y desempeña un papel actancial de líder, que incita a otro a realizar el programa. Asimismo, la figura de Chile es el actante sujeto operador (tiene que hacer) quien por voluntad ejecuta el programa, y posee un papel actancial de Nación. Este actante representa los habitantes, territorio y gobierno que conforman la Nación chilena afectada por la situación ocurrida el 11 de septiembre de 1973 y que deberá construir un país basado en el bienestar social.

Cuando un actante lleva a cabo determinadas acciones que hacen actuar a otro actante, se establece la existencia de un sujeto que debe alcanzar un objetivo que se denomina programa. En el texto analizado el programa identificado corresponde a la construcción de un futuro basado en la paz, el bienestar y la justicia social, y que la Nación (sujeto operador) alcanzará a través del 
recuerdo y la reflexión sobre un acontecimiento catalogado como doloroso (11 de septiembre de 1973).

\section{2) Fase de competencia}

En esta etapa se observa el desarrollo y adquisición de las condiciones necesarias para lograr el programa establecido en la fase de manipulación. Así, el papel actancial de Nación (sujeto operador) en el desarrollo del discurso recuerda reiterativamente el acontecimiento del 11 de septiembre de 1973 (memoria), reflexiona sobre lo ocurrido (reflexión) y valora las acciones en torno al sacrificio hecho por los chilenos.

\section{3) Fase de performancia}

Aquí, la acción realizada por el sujeto operador (Nación) desemboca en el cumplimiento de los objetivos planteados en el proceso de manipulación; es decir, se ha llevado a cabo la acción que transforma la situación inicial del discurso. En este sentido, la Nación ha alcanzado un nivel de progreso significativo basado en la reflexión en torno a las experiencias del pasado y ha construido un país dotado de instituciones renovadas y sólidas, valorando la integración de sus instituciones militares al orden democrático.

\section{4) Fase de sanción}

Una vez alcanzada la transformación, se encuentran nuevamente el actante destinador (Líder) quien en esta etapa desempeña un rol actancial de destinador epistémico, para realizar una evaluación de la acción transformadora realizada por el sujeto operador (Nación) y que la sanciona en función de un sistema de valores. En el caso del discurso, la Nación (sujeto operador) recibe un reconocimiento (recompensa) de parte del destinador epistémico (Líder) por las competencias y performancia alcanzada, situación que se traduce en la valoración de la reconstrucción de la democracia, del afianzamiento de las libertades públicas, convivencia basada en el pluralismo, tolerancia, respeto y unidad del alma na- cional. Lo anterior se enmarca en el programa, donde se entabla la construcción de un país en torno a la obtención de la paz, el bienestar y la justicia social.

\subsection{Identificación de situaciones discursivas}

A través de la lectura y el análisis del texto es posible identificar situaciones discursivas donde las figuras existentes en él poseen recorridos figurativos que al mismo tiempo configuran valores temáticos específicos articulados entre ellos.

La primera situación discursiva existente en el texto se elabora en un primer momento con el saludo protocolar del Presidente Ricardo Lagos a diferentes autoridades y a todos los miembros del país, estableciendo con ello una relación entre el líder y la Nación; entre la figura del Presidente de la República Ricardo Lagos y la figura de Chile.

Fragmento 1: "Señor Nuncio, señores miembros del cuerpo diplomático, señor Cardenal, autoridades religiosas, autoridades civiles, amigos y amigas, chilenos y chilenas..."

En la segunda situación discursiva se incorpora la figura del Presidente Allende a la relación estructurada en la primera situación. Así, esta nueva figura (actor) es empleada por el presidente Ricardo Lagos para identificar un momento determinado de la historia de Chile y entablar una relación de recuerdo (memoria) que conlleva un acto de reflexión a desarrollar por la figura de Chile, entendida esta con la misma dimensión figurativa descrita anteriormente; es decir como Nación.

Fragmento 2: Recogimiento en primer lugar ante un acto grande, muy grande: el sacrificio supremo de un Presidente de La República en cumplimiento de su deber ante la legítima investidura que ostentaba. Un acto de total renunciamiento personal, tal cual lo hicieron otros Jefes de Estado en nuestra historia patria. 
Fragmento 3: Reflexión de un país donde cada día más ese dolor se convierte en memoria, en memoria de todos los chilenos, en memoria compartida, aunque necesariamente común, porque es natural que existan versiones diversas de lo acaecido hace 30 años.

Asimismo, se observa una situación discursiva en la que aparece la figura de tiempo del 11 de septiembre de 1973 (representado por lo acaecido hace 30 años) y la figura de espacio de La Moneda para así determinar la relación existente entre las figuras propuestas en las situaciones anteriores (las figuras del presidente de la República Ricardo Lagos, de Chile y del presidente Allende). En el texto la figura de La Moneda indica el lugar donde se desarrolla la acción discursiva; es decir, el acto de conmemoración de los 30 años del 11 de septiembre de 1973. Por su parte, el 11 de septiembre corresponde a una figura de tiempo que representa un acontecimiento considerado relevante en este discurso y evoca en la memoria de la Nación un momento de dolor.

Fragmento 4: Reflexión de un país donde cada día más ese dolor se convierte en memoria, en memoria de todos los chilenos, en memoria compartida, aunque necesariamente común, porque es natural que existan versiones diversas de lo acaecido hace 30 años.

Fragmento 5: Reflexión, eso sí, de un país que manifiesta su voluntad de que ello no debe volver a ocurrir en nuestra historia. Es un día de invocación espiritual amplia y ecuménica, como lo ha expresado este acto aquí en La Moneda.

La siguiente situación discursiva corresponde al momento en que la figura del presidente de la República, Ricardo Lagos, establece una relación entre la figura del presidente Allende y la figura de Chile en torno a los ideales plasmados en las últimas palabras del presidente Allende (paz, justicia social y bienestar) y que son los pilares fundamentales para la realización de un objetivo.
Fragmento 6: Las últimas palabras del Presidente Allende no fueron expresiones de cólera, menos de resentimiento. Fueron expresiones que aludieron a un futuro de paz, bienestar, de justicia social. Por ello permanecieron, por ello hoy tienen sentido tanto para sus partidarios como para sus detractores. Por eso esas palabras están dirigidas a todos los chilenos y todos los chilenos debemos hacerlas nuestras para construir ese futuro.

Este sentido alcanza toda su plenitud en la medida que hace más grande y generosa el alma de Chile, en la medida que hace más grande y generosa nuestra Patria.

En una posterior situación discursiva desaparece la figura del presidente Allende y es posible identificar una relación de liderazgo entre la figura del Presidente Lagos y la figura de Chile que es originada por las situaciones discursivas donde se describe la relación entre las figuras del presidente Allende, el 11 de septiembre de 1973 y de Chile que es originada por la situación discursiva donde se describe la relación entre la figura del presidente Allende y el 11 de septiembre.

Fragmento 7: Y construir ese futuro es nuestro deber y nuestra tarea. Construir un Chile donde no vuelva a ocurrir jamás lo que hace 30 años ocurrió. Donde jamás los chilenos se vean entre sí como enemigos, donde las diferencias sean parte de la normalidad democrática y no trincheras enfrentadas. Esa es nuestra misión, la de todos nosotros.

Se puede destacar la presente situación discursiva a partir del valor de progreso evidente en la figura de Chile, como consecuencia de la acción evaluadora que ejerce la figura del presidente de la República Ricardo Lagos en el discurso. Asimismo, la figura de la Moneda es utilizada en la presente situación discursiva como un referente de la confirmación de la democracia.

Fragmento 8: Misión que por fortuna, como todos sabemos, está en curso y a la 
que por lo tanto, no tenemos hoy que dar inicio, sino que tenemos que continuar llevándola adelante.

Fragmento 9: Lo avanzado en nuestra convivencia no es sólo mérito de quienes hemos ejercido el Gobierno del país en estos años. Es mérito de todos los chilenos y chilenas, de sus trabajadores y de sus emprendedores, del conjunto de las instituciones, de las fuerzas morales, intelectuales y creativas del país, muchos de cuyos representantes están hoy aquí y nos acompañan en este acto.

Fragmento 10: Ese Chile libre que cristaliza en la apertura de las puertas de La Moneda y donde hoy se ha restablecido la tradicional puerta que simboliza nuestro sello republicano.

Finalmente, encontramos una situación discursiva donde la relación de la figura del presidente de la República, Ricardo Lagos, y la figura de Chile está mediada por la figura del 11 de septiembre de 1973 y por los objetivos planteados en la cuarta situación discursiva (paz, justicia social, pluralismo, afianzamiento de las libertades, etc.) y que estructuran el programa del texto.

Fragmento 11: Así y sólo así ese sacrificio de hace 30 años cobrará todo su sentido. Sólo así las anchas alamedas finalmente se abrirán para todos los hijos de esta tierra.
Chile con su memoria completa y no fragmentada será cada vez más un país más humano, más unido, más confiado.

Será un Chile mejor.

Será un Chile, como dice la cantata en su coro que acabamos de escuchar, 'una ciudad yo quisiera/ construida en libertad/ un mundo ancho y abierto/ donde podamos amar'.

\section{Conclusiones del trabajo}

A partir de los resultados obtenidos podemos concluir que existe una representación ordenada y lógica del texto analizado a partir de los enunciados que se construyen en referencia al acontecimiento histórico del Golpe Militar de 1973 en Chile y que, por lo demás, ha determinado una cristalización dicotómica acerca del evento histórico en la memoria colectiva del país. Lo anterior se observa con claridad, en la medida que el discurso presidencial logra reconstrucción las redes de significación y los recorridos históricos mediante relaciones de contrariedad, de contradicción y de complementariedad para esbozar así el sentido del discurso.

De este modo, el análisis del discurso presidencial establece las bases de un imaginario social (sistemas de significación subyacentes) en torno a los 30 años del 11 de septiembre de 1973, a partir de una tríada de oposiciones existentes en el nivel lógico-semántico y que corresponde a las siguientes relaciones:

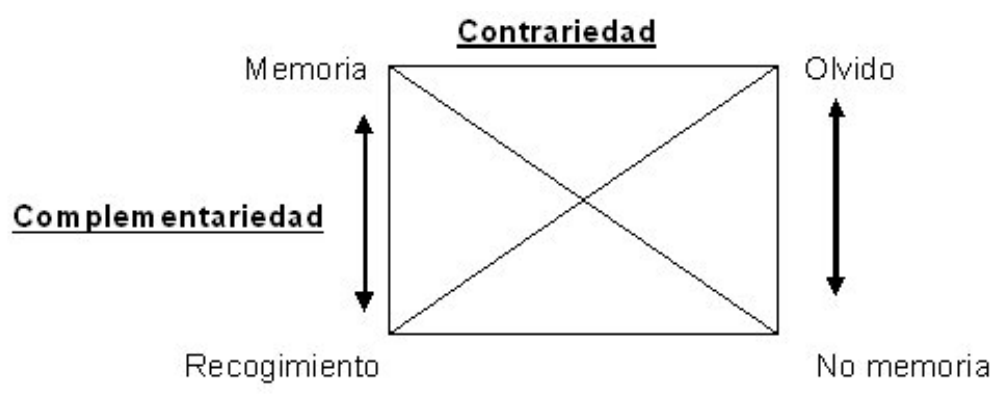

Fig. I. Elaboración propia. Relaciones semióticas en torno a los 30 años del Golpe Militar en Chile 


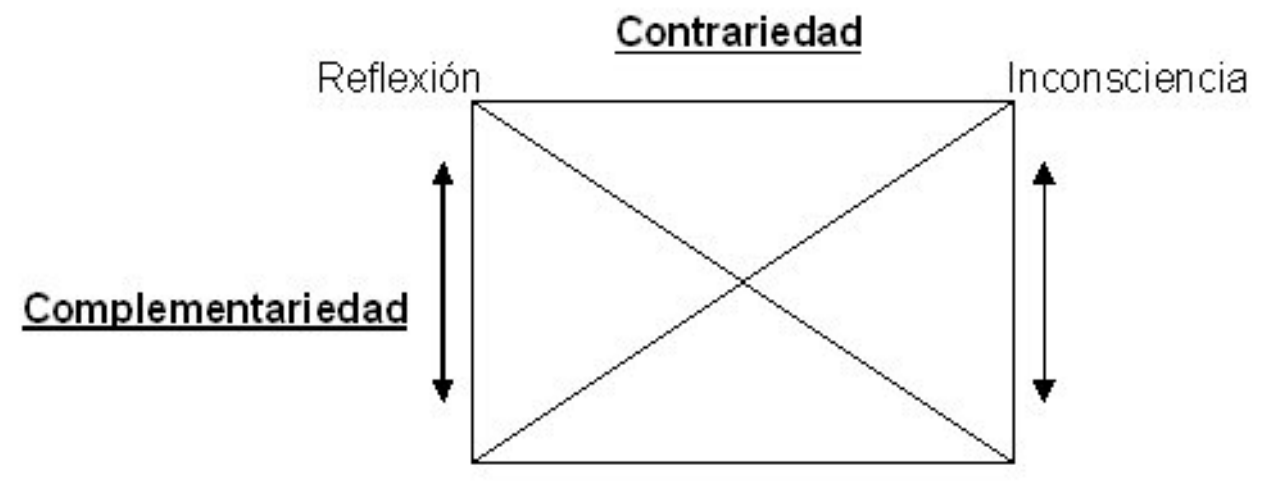

No inconsciencia

No reflexión

Fig. II. Elaboración propia. Relaciones semióticas en torno a los 30 años del Golpe Militar en Chile

La oposición designada como "Memoria-Olvido" tiene un valor de significación fundamental en el discurso, ya que la figura del presidente de la República, Ricardo Lagos (nivel discursivo), en el desarrollo del texto relaciona las figuras del presidente Allende y la figura del 11 de septiembre de 1973 para apelar a la "memoria colectiva" que se tiene de un acontecimiento y, de esta manera, emprender la reflexión que permita construir un país basado en las ideas de paz, bienestar y justicia social. ${ }^{12}$.

Por su parte, en el nivel narrativo esta oposición se caracteriza por la relación en la fase de hacer-hacer, en la cual el sujeto operador del discurso tiene que cumplir con el programa determinado que se sustenta en el valor de memoria

12 Fragmentos (F) del discurso presidencial en conmemoración de los 30 años del 11 de septiembre de 1973.

(F1) "Es un día para la memoria, para hacernos cargo con madurez de aquel momento de nuestra historia que tanto dolor nos ha causado".

(F2) "Recogimiento en primer lugar ante un acto grande, muy grande: el sacrificio supremo de un Presidente de la República en cumplimiento de su deber ante la legítima investidura que ostentaba. Un acto de total renunciamiento personal, tal cual lo hicieron otros Jefes de Estado en nuestra historia patria".

(F3) "Reflexión de un país donde cada día más ese dolor se convierte en memoria, en memoria de todos los chilenos, en memoria compartida, aunque no necesariamente común, porque es natural que existan versiones diversas de lo acaecido hace 30 años". como eje articulador de las demás figuras y papeles actanciales.

Otra oposición presente en el texto analizado es la de Reflexión-Inconsciencia ${ }^{13}$, que funciona de forma dependiente de la relación anterior, ya que su significación en el texto está dada por la presencia de la figura del 11 de septiembre de 1973 y la del presidente Allende que es empleada por la figura del presidente de la República, Ricardo Lagos, para evocar el recuerdo y la acción reflexiva como forma de motivar e impulsar el desarrollo del país, de manera que ese momento cobre un sentido completo en la historia de Chile.

13 (F4) "Reflexión de un país donde cada día más ese dolor se convierte en memoria, en memoria de todos los chilenos, en memoria compartida, aunque no necesariamente común, porque es natural que existan versiones diversas de lo acaecido hace 30 años".

(F5) "Reflexión, eso sí, de un país que manifiesta su voluntad de que ello no debe volver a ocurrir en nuestra historia. Es un día de invocación espiritual amplia y ecuménica, como lo ha expresado este acto aquí en La Moneda".

(F6) "Es también un día de valoración de quienes a partir de esos momentos de dolor y de tragedia encarnaron lo mejor del ser humano, protegieron a los perseguidos, lucharon por los derechos humanos".

(F7) "Es también un día de reflexión sobre el sentido de ese sacrificio. Y este sentido no puede ser ni de rencor ni de división".

(F8) "Construir un Chile donde no vuelva a ocurrir jamás lo que hace 30 años ocurrió. Donde jamás los chilenos se vean entre sí como enemigos, donde las diferencias sean parte de la normalidad democrática y no trincheras enfrentadas. Esa es nuestra misión, la de todos nosotros". 


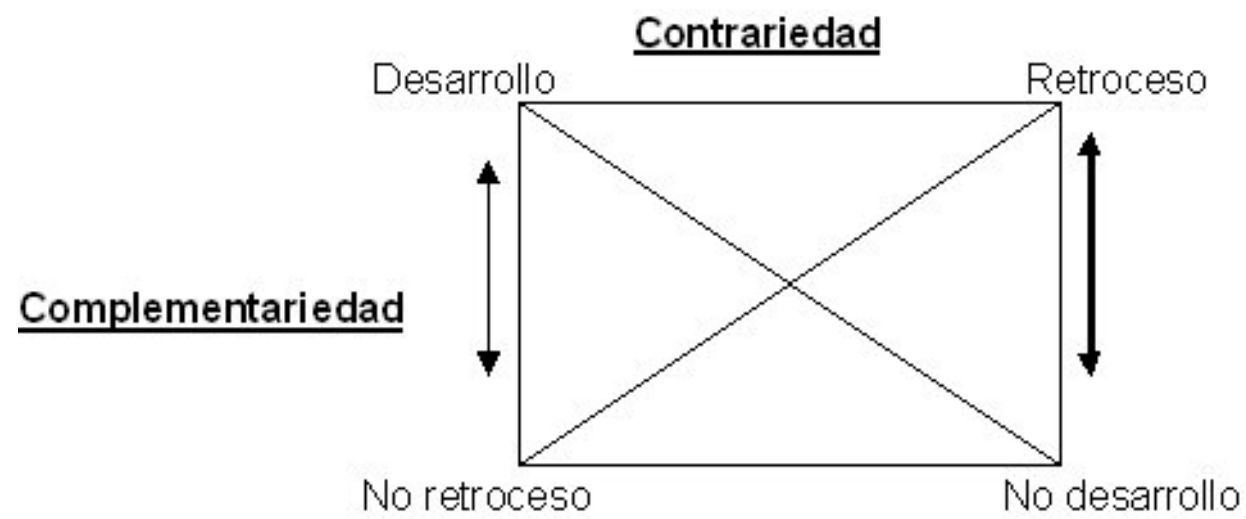

Fig. III. Elaboración propia. Relaciones semióticas en torno a los 30 años del Golpe Militar en Chile

Finalmente, se observa en el discurso la oposición de Desarrollo-Estancamiento ${ }^{14}$ que da cuenta del efecto discursivo que surge a partir de las lógicas alcanzadas en las oposiciones anteriores. De esta forma, se establece la relación entre la memoria, recuerdo de un momento histórico de Chile, y el proceso reflexivo permanente sobre dicho momento. Alcanzar esta relación le permite a Chile encauzar un camino de desarrollo sustentado en la reflexión y la memoria, situación que evidencia en el discurso una relación entre las figuras identificadas en el plano discursivo y el proceso de estas figuras en las cuatro fases del nivel narrativo.

14 (F9) "Lo avanzado en nuestra convivencia no es sólo mérito de quienes hemos ejercido el Gobierno del país en estos años. Es mérito de todos los chilenos y chilenas, de sus trabajadores y de sus emprendedores, del conjunto de las instituciones, de las fuerzas morales, intelectuales y creativas del país, muchos de cuyos representantes están hoy aquí y nos acompañan en este acto".

(F10) "En este día el mundo vuelve sus ojos hacia este lugar, que remeció la conciencia de la humanidad hace 30 años. Pero a la vez podemos hoy mirar al mundo para mostrar un país que está en la senda de la esperanza, de la fraternidad y de la justicia a la que se refirió el Presidente mártir".

(F11) "En unos días más, al inicio de la primavera, estaremos celebrando 15 años del triunfo que nos puso nuevamente a caminar y a transitar por los caminos de la democracia que abrió paso al Chile de hoy".

(F12) "A ese Chile que goza de un enorme prestigio en el mundo por su progreso, por el ejercicio de sus libertades, por la solidez de sus instituciones, por la plena integración de sus instituciones militares al orden democrático".

\section{Referencias bibliográficas}

Agamben G. 2003. Profanaciones. Barcelona: Anagrama.

Baeza, Manuel Antonio. 2008. Mundo real, mundo imaginario social. Teoría y práctica de sociología profunda. Santiago de Chile: RIL Editores.

Baeza, Manuel Antonio. 2003. Imaginarios sociales. Apuntes para la discusión teórica y metodológica. Chile: Editorial Universidad de Concepción.

Castoriadis, Cornelius. 2007. La institución imaginaria de la sociedad. Buenos Aires: Tusquets Editores.

Castoriadis, Cornelius. 2001. Figuras de lo pensable. Las encrucijadas del laberinto VI. México: Fondo de Cultura Económica.

Costa, Ricardo y Mozejko, Danuta. 2001. El discurso como práctica. Lugares desde donde se escribe la historia. Rosario: Homo Sapiens Ediciones.

Courtés, Joseph. 1995. Análisis semiótico del discurso.Del enunciado a la enunciación. Madrid: Editorial Gredos.

Gadamer, Hans Georg. 1998. Verdad y Método Vol. II. Salamanca: Ediciones Sígueme.

Garretón, Manuel Antonio. 2003. Memoria y proyecto de país, en Revista de Ciencia Política. Vol. XXIII, $N^{\circ}$ 2. Pontificia Universidad Católica de Chile. pp. 215-230. 
Garretón, Manuel Antonio. 2000. La sociedad en que vivi(re) mos. Introducción sociológica al cambio de siglo. Santiago de Chile: LOM.

Giroud, Jean-Claude y Panier, Louis. 1988. Semiótica. Navarra: Verbo Divino.

Halbwachs, Maurice. 2004. La memoria colectiva. Zaragoza: Prensas Universitarias de Zaragoza.

Jäger, Siegfried. 2003. Discurso y conocimiento: Aspectos teóricos y metodológicos de la crítica del discurso y del análisis de dispositivos, en Wodak, Ruth y Meyer, Michael (ed.). Métodos de análisis crítico del discurso. Barcelona: Gedisa.

Kaës, René. 2006. Rupturas catastróficas y trabajo de la memoria. Notas para una investigación, en Puget, Janine y Kaës, René (comp). 2006. Violencia de Estado y psicoanálisis. Buenos Aires: Lumen.
Kristeva, Julia. 2007. Acerca de Iuri Lotman. Entretextos n. ${ }^{\circ} 10$, granada noviembre 2007, pp. 1-3.

Larraín, Jorge. 2007. El concepto de ideología Vol 1: Carlos Marx. Santiago de Chile: LOM.

Lotman, Iuri. 1996. La Semiosfera I. Semiótica de la cultura $y$ del texto. Madrid: Frónesis.

O`Donnell, Guillermo. 1993. Estado, democratización y ciudadanía, en Revista Nueva Sociedad. N. ${ }^{\circ} 128$. pp. 62-87.

Peñamarín, Cristina. 2006. "Malentendido intercultural e intracultural. Comunicación" n. ${ }^{\circ}$ 4, pp. 141-155.

Pintos, Juan Luis. 2005. Comunicación, construcción de la realidad e imaginarios sociales, en Revista Utopía y Praxis Latinoamericana. Año 10. № 29. pp. 37-65. 
